\title{
DESIGN OF EXPANSION ANCHORS TO CONCRETE BASED ON RESULTS OF EXPERIMENTAL VERIFICATION
}

\author{
Marcela Karmazínová * , Jindrich Melcher and Zdenek Kala \\ Brno University of Technology, Veveři St. 95, 60200 Brno, Czech Republic \\ *(Corresponding author: E-mail: karmazinova.m@fce.vutbr.cz)
}

Received: 24 January 2008; Revised: 24 July 2008; Accepted: 28 July 2008

\begin{abstract}
This paper deals with the problems of the fastening of steel structures to concrete constructions using the post-installed anchoring elements. The paper is oriented to the presentation of some results of the analysis concentrated to the actual behaviour of the particular type of steel mechanical anchors, so called expansion anchors, during the loading process. Within the frame of the experimental verification, using the realized tests results and their elaboration, the load-carrying capacities for the corresponding failure mechanisms were obtained. Within the frame of the theoretical analysis, using the tests results statistic evaluation, the probabilistic models were created, for the subsequent reliability analysis leading to the derivation of the characteristic and design resistances. The problems mentioned above were solved for some selected failure mechanisms and load-carrying capacities of expansion anchors under tensile force namely, for static loading actions and eventually for dynamic loading actions.
\end{abstract}

Keywords: Fastening, expansion anchors, steel, concrete, experiment, design assisted by testing, design resistance, characteristic resistance, mean value

\section{INTRODUCTION}

The effectiveness and accurate placement together with the new easy techniques and technology are the most important advantages of the post-installed anchor systems increasingly used for the connection of other structural or constructional parts to hardened concrete and masonry supporting structures.

In the new construction as well as in repair and strengthening works the anchor behaviour can be rather complicated considering the influence of concentrated loads, their different direction and especially the type of the failure mode depending on the way of the load transfer from anchor body into the concrete or masonry base. Thus the experimental verification together with statistical analysis of appropriate results should be an authority for the theoretical modelling and practical design procedures of the fastening systems. Recently a wide range of post-installed anchor systems have been developed. Well-known producers in this area are HILTI or FISCHER for example (http://www.hilti.com and http://www.fischer.de). The application of fastening systems to reinforced concrete and masonry, in general, is based on experimental and theoretical investigations and continuous work of international technical groups and committees, for example.

In this paper the brief information on analysis of results of the experimental research program directed to problems of actual behaviour of torque-controlled expansion anchors produced in our country is presented. 


\section{BASIC INFORMATION OF EXPERIMENTAL RESEARCH PROGRAMME}

During recent decade, in our workplace, the research oriented to the anchorage to concrete or masonry is developed. As one of the parts of this research the large experimental programme of steel expansion anchors to concrete was realized in our testing laboratory. Within the frame of the realized experimental programme the expansion anchors under tension static loading and also tension cyclic loading and under shear static loading were tested. These tests were directed to the experimental verification of the actual behaviour of the investigated anchor elements - so called torque-controlled expansion anchors (see Figure 1). The strain mechanisms during the loading processes and the failure mechanisms with the corresponding load-carrying capacities were monitored, especially. As follows, the partial results of the design resistance of steel expansion anchors to concrete loaded by static tensile force or static shear force, obtained from the experimental verification and the probabilistic analysis, are presented.

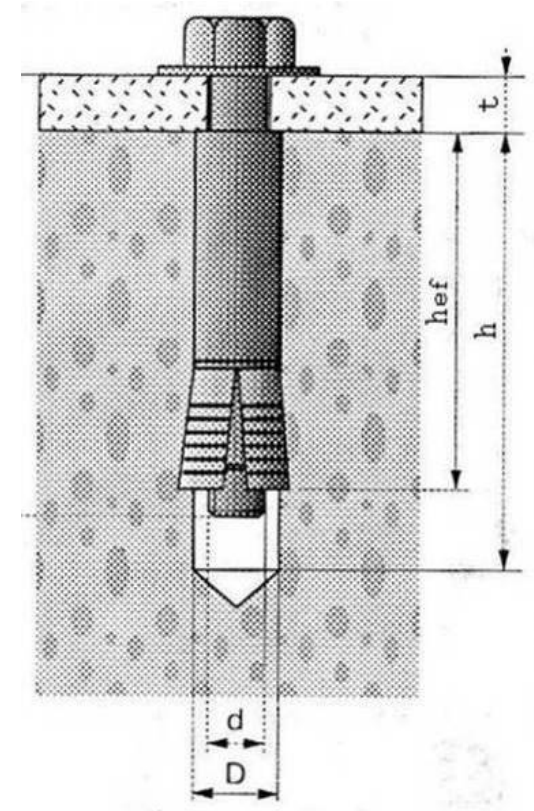

Figure 1. Typical Scheme of Torque-Controlled Expansion Anchor

So far the results of 343 tests of torque-controlled expansion anchors to concrete under static loading actions and 58 tests of anchors under cyclic loading actions (in the first part 13 "pilot" tests and later 45 continuing "new" tests), in both cases by tensile force, have been elaborated. Among 343 tests of expansion anchors under static loading by tensile force (239 tests) and also by shear force (104 tests) the typical failure mechanisms and corresponding load-carrying capacities have been obtained as the bases for the anchor resistances determination. Among 58 tests of expansion anchors under cyclic (repeated) loading by tensile force the typical failure mechanisms and corresponding load-carrying capacities have been obtained too. The research directed towards the experimental verification of the actual behaviour and load-carrying capacity of expansion anchors to concrete is continuing and the set of about 150 results of newly tested specimens (for loading cases mentioned above) is prepared for the following elaboration but so far these tests results have not been evaluated quietly, so these new tests results are not included to the information here presented. 


\section{EXPANSION ANCHORS TO CONCRETE UNDER STATIC LOADING BY TENSILE FORCE}

For the test specimens under tensile loading the expansion torque-controlled anchors according to Figure 1 with following parameters have been used: For the anchor bolts the steel grade of $8.8-$ with the nominal values of ultimate tensile strength $f_{u b}=800 \mathrm{MPa}$, and diameters of $d=10,12$ and $16 \mathrm{~mm}$ have been used. The external diameters of anchor sleeve have been $D=14,18$ and $24 \mathrm{~mm}$. The concrete cube strength $f_{c c}$ of the specimen bodies was in the range about from $20 \mathrm{MPa}$ to $70 \mathrm{MPa}$ and the effective anchor embedment depth $h_{e f}$ was in the range from $50 \mathrm{~mm}$ to $80 \mathrm{~mm}$.

For anchors to concrete under tension loading (realized by axial tensile force action) the following basic types of failure modes - steel failure mode or concrete failure mode can occur. Because steel bolt failure mode and its corresponding strength are generally known the solution was directed to the concrete failure, namely.

\subsection{Concrete-Cone Failure Mode for Anchor in Large Edge Distance}

For the large edge distance of anchor the concrete-cone failure (see Figure 2) occurred in 86 cases of tests. Based on two methods most often used for the determination of concrete-cone failure load-carrying capacity - so called "Concrete Cone Method" and "Concrete Capacity Method" (Eligehausen [1]) - load-carrying capacity mean values have been determined (Karmazínová et al. [2-4]), (Karmazínová $[5,6]$ ), by the regression analysis used for the comparison of the test and theoretical results.
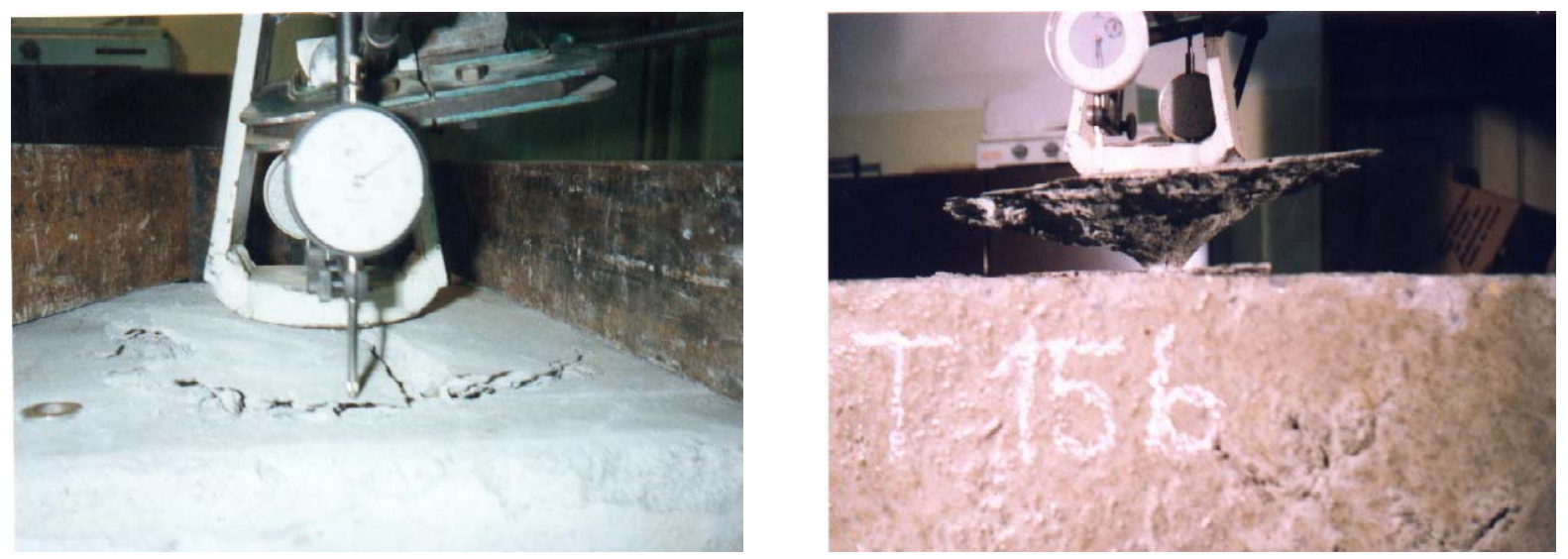

Figure 2. Illustration of Concrete-Cone Failure Mode: Tension Loading, Anchor in Large Edge Distance

For "ACI - method" (ACI - American Concrete Institute) based on the "Concrete Cone Method" (see Figure 3a) the mean value of the load-carrying capacity using the test results can be given by the format of

$$
N_{u m}=0.74 \cdot \pi \cdot h_{e f}^{2} \cdot f_{c c}^{0.5} \quad[\mathrm{~N}],
$$

where $h_{e f}$ is the effective anchorage depth (see Figures 1 and 3 ) and $f_{c c}$ is the concrete cube strength. For so called " $\psi$ - method" (in the name of this method $\psi$ represents the general symbol for coefficients of various parameters influencing load-carrying capacity) based on the principle of "Concrete Capacity Method" (see Figure 3b), the mean value of the load-carrying capacity using the test results can be given by the equation of 


$$
N_{u m}=16.8 \cdot h_{e f}^{1.5} \cdot f_{c c}^{0.5} \quad[\mathrm{~N}]
$$

Usually in formulas for the load-carrying capacity determination - see (1), (2), the effective anchor depth $h_{e f}$ and concrete cube strength $f_{c c}$ are considered only but in some cases (short anchors, e.g.) for the more exact expression of the load-carrying capacity it is suitable to take into account also the sleeve diameter $D$. Based on Eq. 1 and considering the anchor sleeve diameter $D$ as the added parameter the mean value of load-carrying capacity using the test results can be given by the format of

$$
N_{u m}=0.56 \cdot \pi \cdot h_{e f}^{2} \cdot f_{c c}^{0.5} \cdot\left(1+\frac{D}{h_{e f}}\right) \quad[\mathrm{N}] .
$$

Similarly, based on Eq. 2 and taking into account the anchor sleeve diameter $D$ the mean value of load-carrying capacity can be written as

$$
N_{u m}=13.2 \cdot h_{e f}^{1.5} \cdot f_{c c}^{0.5} \cdot\left(1+\frac{D}{h_{e f}}\right) \quad[\mathrm{N}] .
$$

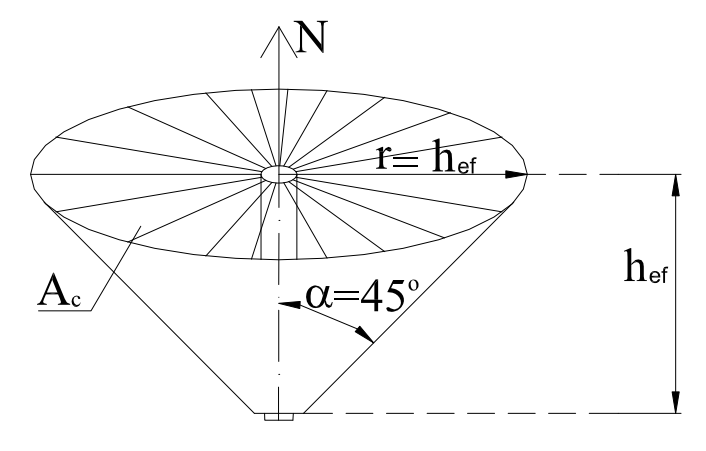

a) $A C I-$ Method

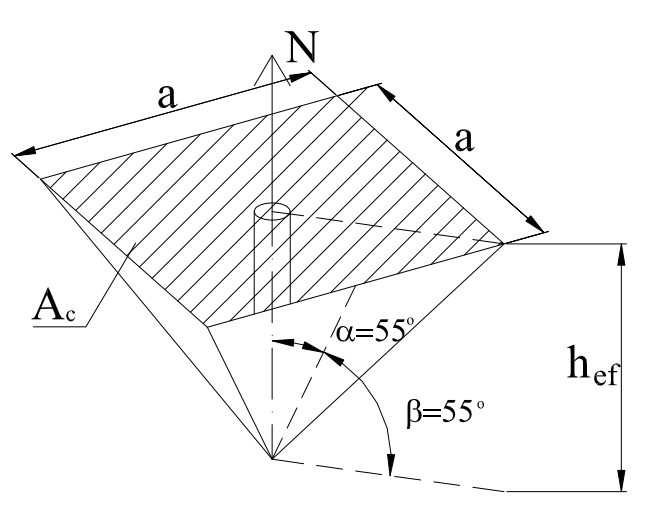

b) $\psi-$ Method

Figure 3. Principles of " $A C I$ " and " $\psi$ " Methods - Concrete-Cone Failure Mode: Tension Loading, Anchor in Large Edge Distance

The elaboration of the test results based on the statistical evaluation of the actual objective load-carrying capacities was directed to the determination of the mean values and their corresponding statistical parameters and then to the determination of the characteristic values and design values of the load-carrying capacities applying the methods of design assisted by testing.

For the methods mentioned above $(A C I, \psi$ or the methods considering the diameter $D)$ the statistical characteristics (mean values, standard deviations and variation coefficients) of the ratio of the experimental values to the mean values calculated according to (1) or (2) and (3) or (4) are seen in Table 1. 
Table 1. Statistical Parameters of the $N_{u, e x} / N_{u m}$ Ratios

\begin{tabular}{|c|c|c|c|}
\hline Statistic Analysis & Mean Value $m$ & Stand. Deviation $s$ & Var. Coefficient $v$ \\
\hline$N_{u m}$ according to (1) & 1.086 & 0.302 & 0.278 \\
\hline$N_{u m}$ according to (2) & 0.990 & 0.246 & 0.248 \\
\hline$N_{u m}$ according to (3) & 1.057 & 0.265 & 0.251 \\
\hline$N_{u m}$ according to (4) & 0.972 & 0.224 & 0.231 \\
\hline
\end{tabular}

These statistical parameters can give general view about the differences between experimental values and theoretical mean values.

In the following Figures 4 and 5, for the graphic illustration of the equations for the mean values of load-carrying capacity the ratios of experimental to mean values $N_{u, e x} / N_{u m}$ are shown. In Figure 4 for the Eqs. 1-4 the ratios $N_{u, e x} / N_{u m}$ depending on the effective embedment depth $h_{e f}$ are drawn; in Figure 5, for the Eqs. 3 and 4 taking into account the sleeve diameter of $D$ the ratios $N_{u, e x} / N_{u m}$ depending on the anchor sleeve diameter $D$ and also depending on the ratio of $D / h_{e f}$ respectively (for better illustration), are plotted.

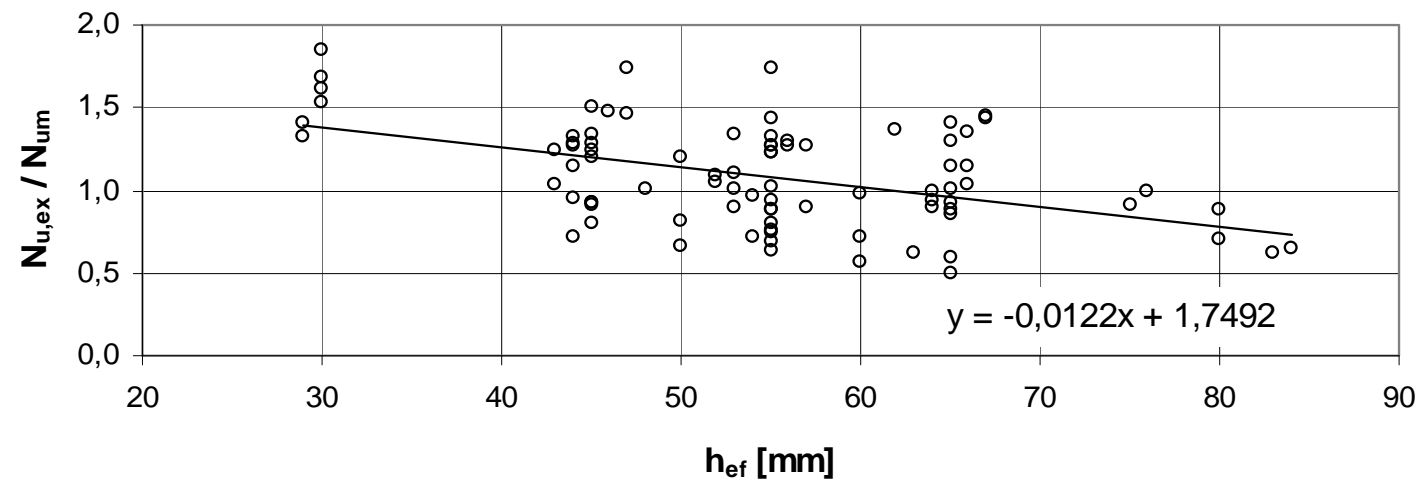

a) Mean Value According to (1)

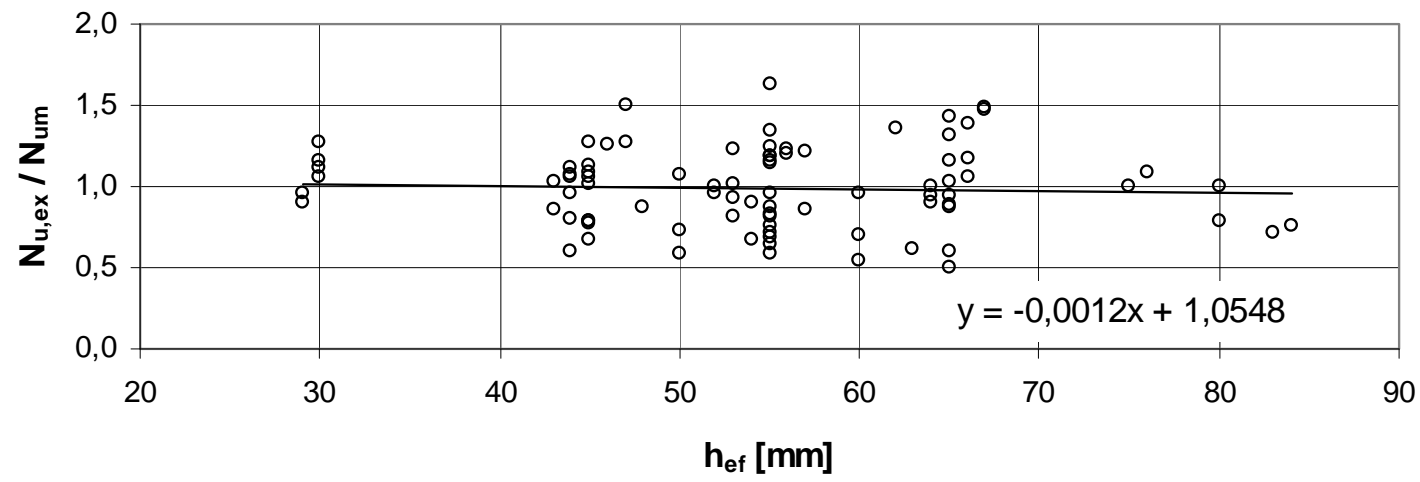

b) Mean Value According to (2) 


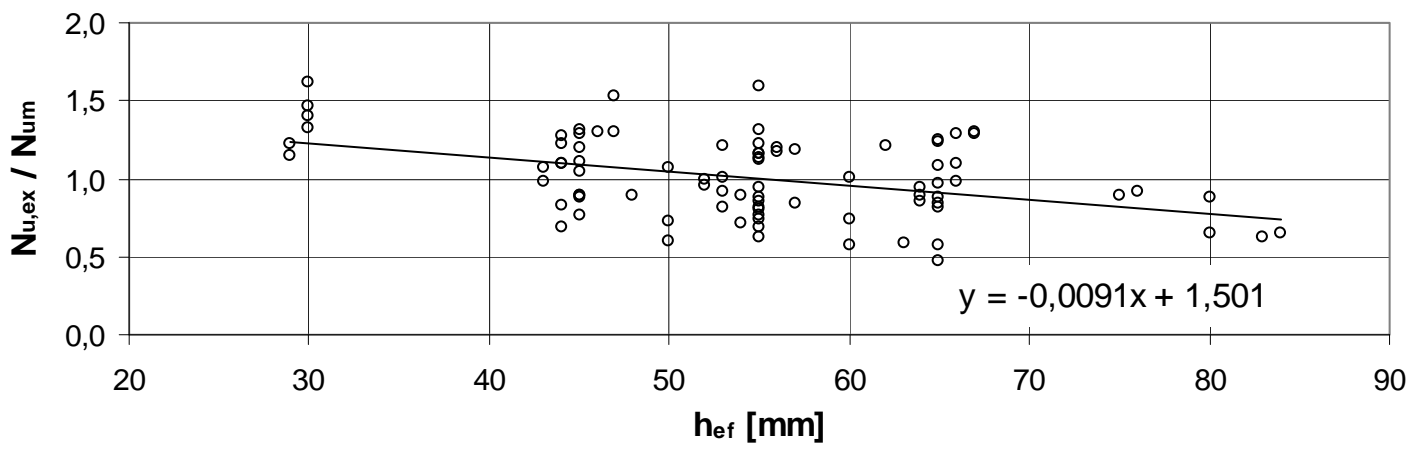

c) Mean Value According to (3)

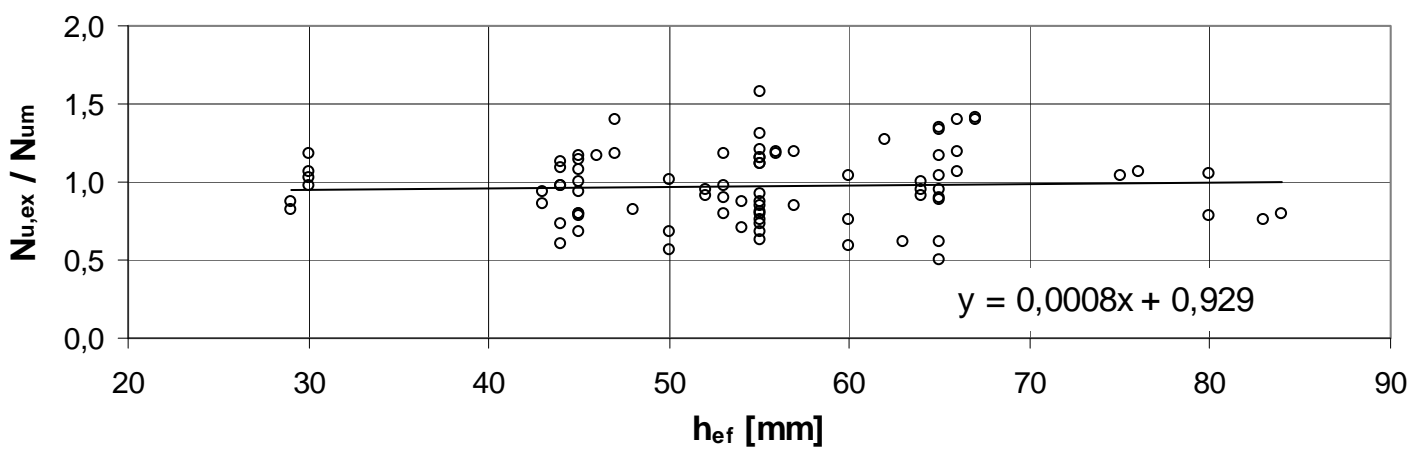

d) Mean Value According to (4)

Figure 4. Ratios of Experimental to Mean Values $N_{u, e x} / N_{u m}$ Depending on $h_{e f}$
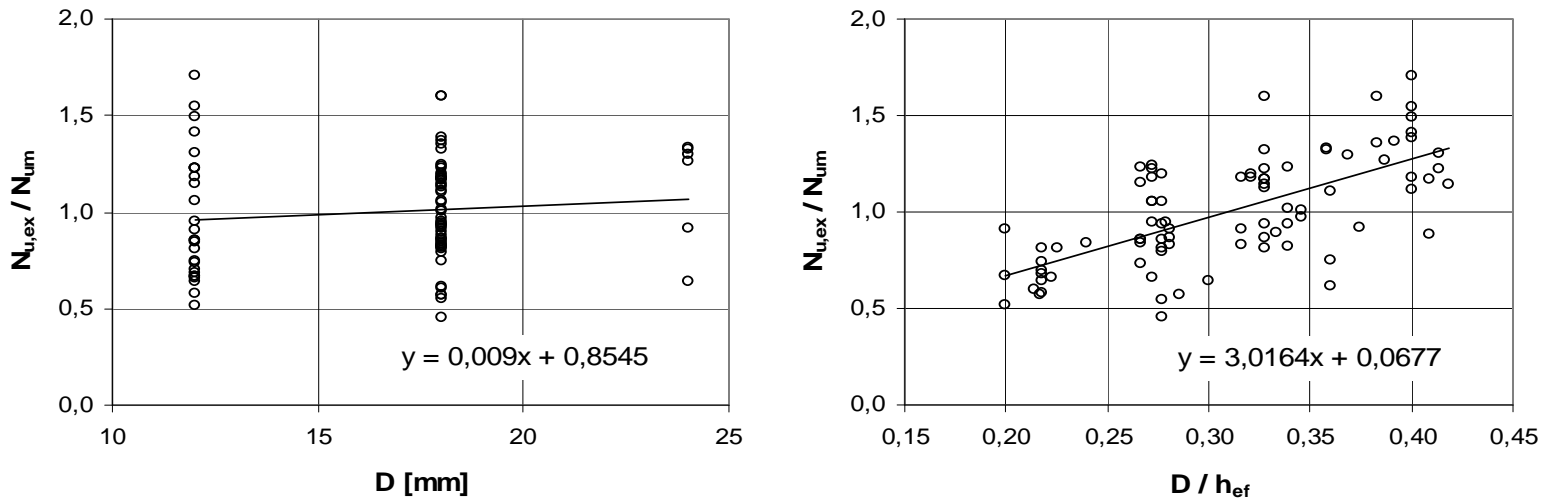

a) Mean Value According to (3)
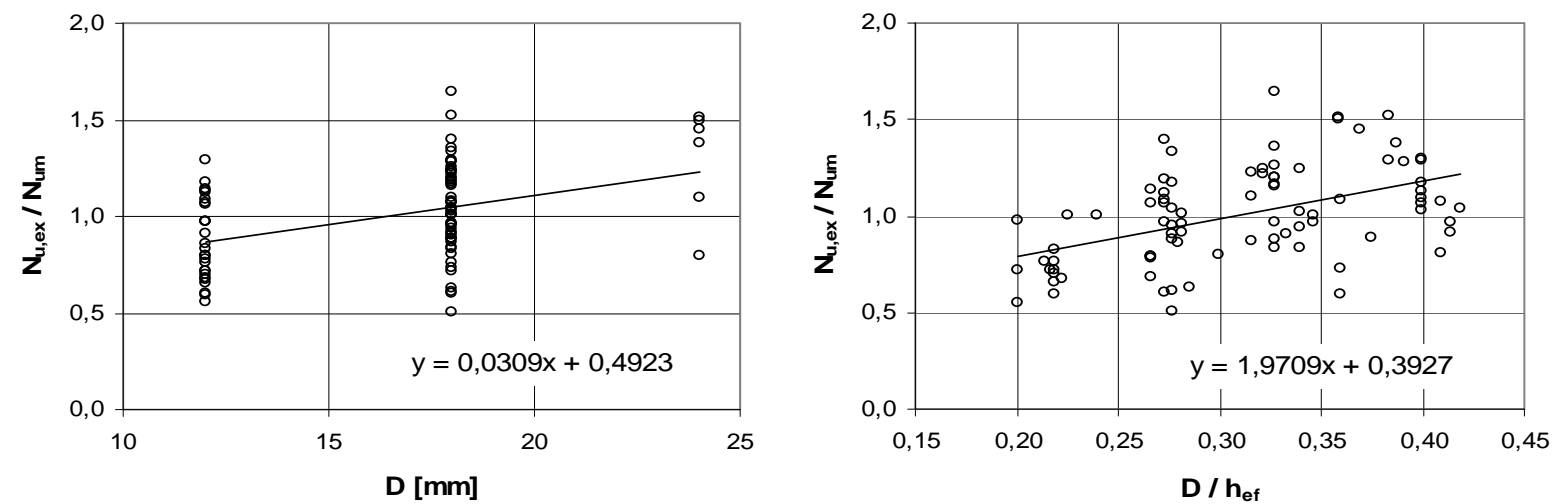

b) Mean Value According to (4)

Figure 5. Ratios of Experimental to Mean Values $N_{u, e x} / N_{u m}$ Depending on $D$ or $D / h_{e f}$ 
The formulas in the format of Eqs. 1, 2 or 3, 4 respectively, are generally useful for the determination of the load-carrying capacity for the anchors in tension. Here, for basic input random variables the variation coefficients were considered as follows: the variation coefficient of effective anchorage depth $v_{\text {hef }}=0.03$; the variation coefficient of concrete cube strength $v_{f c c}=0.20$; the variation coefficient of sleeve diameter $v_{D}=0$ ( $D$ was considered deterministically). Consequently, using the standard procedure for characteristic and design resistances determination (EN 1990 [7]), we can obtain the characteristic value $N_{k}$ and the design value $N_{d}$ of load-carrying capacity for the expansion anchor in tension (Karmazínová et al. [2, 4, 6]) as:

for the mean value according to Eq. 1

$$
\begin{aligned}
& N_{k}=0.38 \cdot \pi \cdot h_{e f}^{2} \cdot f_{c c}^{0.5} \quad[\mathrm{~N}], \\
& N_{d}=0.24 \cdot \pi \cdot h_{e f}^{2} \cdot f_{c c}^{0.5} \quad[\mathrm{~N}],
\end{aligned}
$$

for the mean value according to Eq. 2

$$
\begin{aligned}
& N_{k}=10.2 \cdot h_{e f}^{1.5} \cdot f_{c c}^{0.5} \quad[\mathrm{~N}], \\
& N_{d}=6.7 \cdot h_{e f}^{1.5} \cdot f_{c c}^{0.5} \quad[\mathrm{~N}],
\end{aligned}
$$

for the mean value according to Eq. 3

$$
\begin{aligned}
& N_{k}=0.313 \cdot \pi \cdot h_{e f}^{2} \cdot f_{c c}^{0.5} \cdot\left(1+\frac{D}{h_{e f}}\right) \quad[\mathrm{N}], \\
& N_{d}=0.204 \cdot \pi \cdot h_{e f}^{2} \cdot f_{c c}^{0.5} \cdot\left(1+\frac{D}{h_{e f}}\right) \quad[\mathrm{N}],
\end{aligned}
$$

for the mean value according to Eq. 4

$$
\begin{aligned}
& N_{k}=7.89 \cdot h_{e f}^{1.5} \cdot f_{c c}^{0.5} \cdot\left(1+\frac{D}{h_{e f}}\right) \quad[\mathrm{N}], \\
& N_{d}=5.36 \cdot h_{e f}^{1.5} \cdot f_{c c}^{0.5} \cdot\left(1+\frac{D}{h_{e f}}\right) \quad[\mathrm{N}] .
\end{aligned}
$$




\subsection{Lateral Concrete-Cone Failure Mode for Anchor in Small Edge Distance}

In 61 cases of tests, for the small edge distance of anchors, the lateral concrete-cone failure mode or edge failure mode occurred (see Figure 6). Considering those two basic methods mentioned above the load-carrying capacity for anchor closed to the edge was determined as the load-carrying capacity for the large edge distance reduced by the edge influence. Usually the load-carrying capacity for full concrete-cone failure mode is decreased using the reduced projected area (see Figure 7).
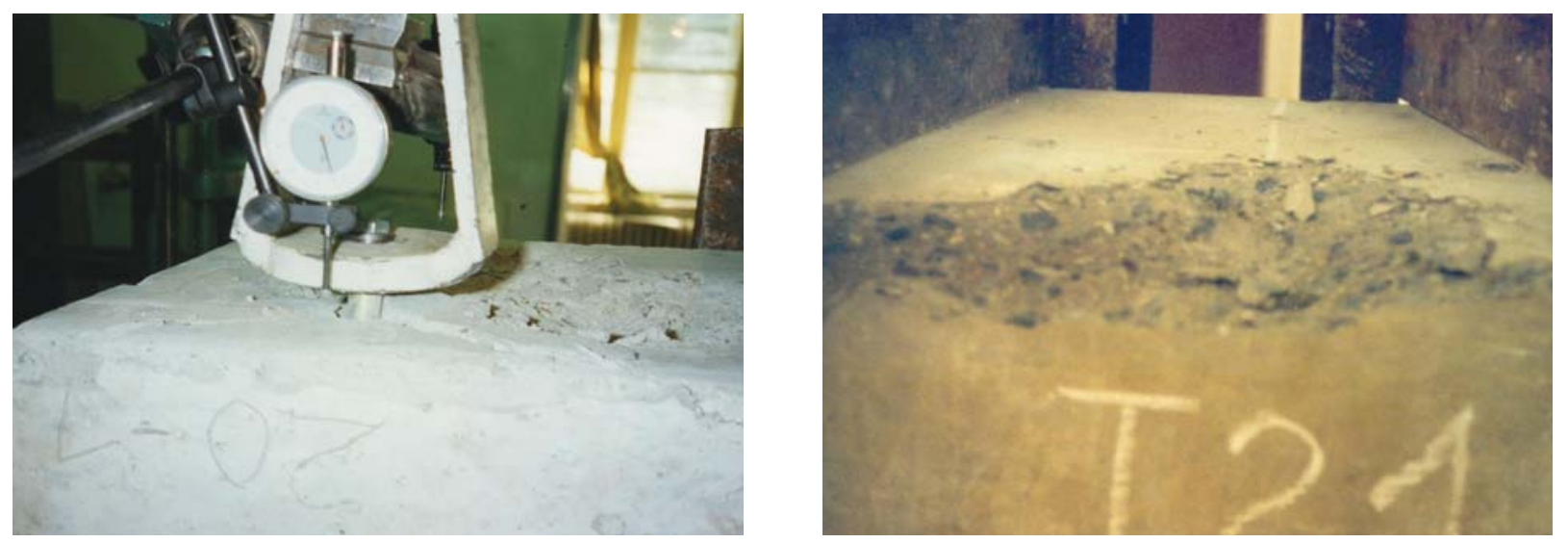

Figure 6. Illustration of Lateral Concrete-Cone Failure (Edge Failure) Mode:

Tension Loading, Anchor in Small Edge Distance
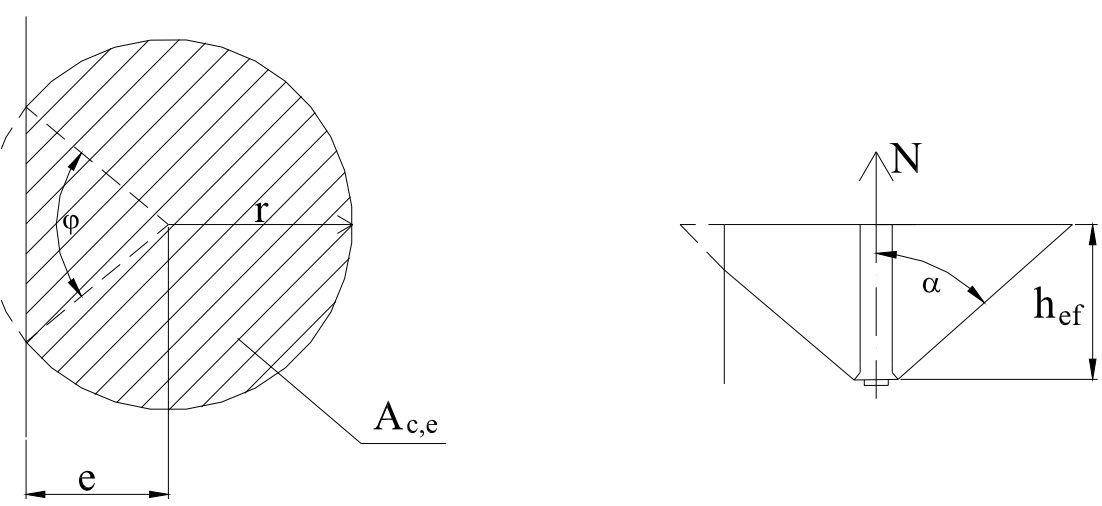

Figure 7. Principle of the Reduced Projected Area - Lateral Concrete-Cone Failure Mode:

Tension Loading, Anchor in Small Edge Distance

The mean value of load-carrying capacity (Karmazínová et al. [2, 6]) with the edge influence $N_{u m, e}$ can be written in the form of

$$
N_{u m, e}=\left(0.2+0.8 \cdot \frac{e}{e_{c r}}\right) \cdot N_{u m}
$$

where $N_{u m}$ is the mean value of load-carrying capacity for full concrete-cone failure mode according to Eq. 1, or respectively, in the form of 
$N_{u m, e}=\left(0.3+0.7 \cdot \frac{e}{e_{c r}}\right) \cdot N_{u m}$

where $N_{u m}$ is the mean value of load-carrying capacity according to Eq. 2, but in the most simple case in the form of

$N_{u m, e}=\frac{e}{e_{c r}} \cdot N_{u m}$

where $N_{u m}$ can be the mean value according to both expressions, Eqs. 1 or 2 too. In all Eqs. 13-15: $e$ is the edge distance and $e_{c r}=2 h_{e f}$ is so called critical edge distance for the full concrete-cone failure.

For the mean value $N_{u m}$ expressed by Eq. 1 the relationships between the ratios of $N_{u m . e} / N_{u m}$ and $e / h_{e f}$ according to Eqs. 13 and 15 are drawn in Figure 8. For $N_{u m}$ expressed by Eq. 2 the similar relationships according to Eqs. 14 and 15 too are shown in Figure 9.

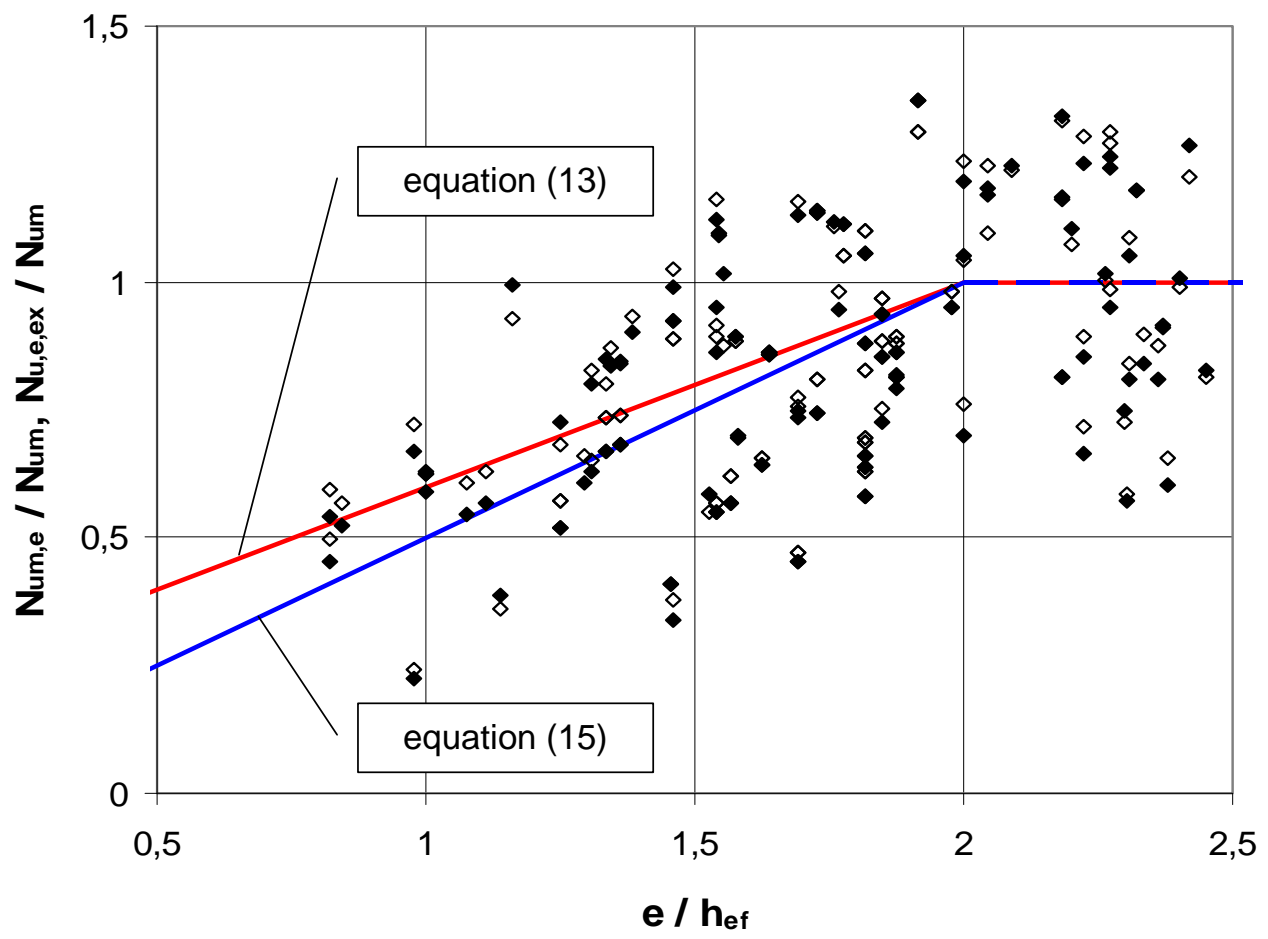

Figure 8. Relationships According to Eqs. 13 and 15 


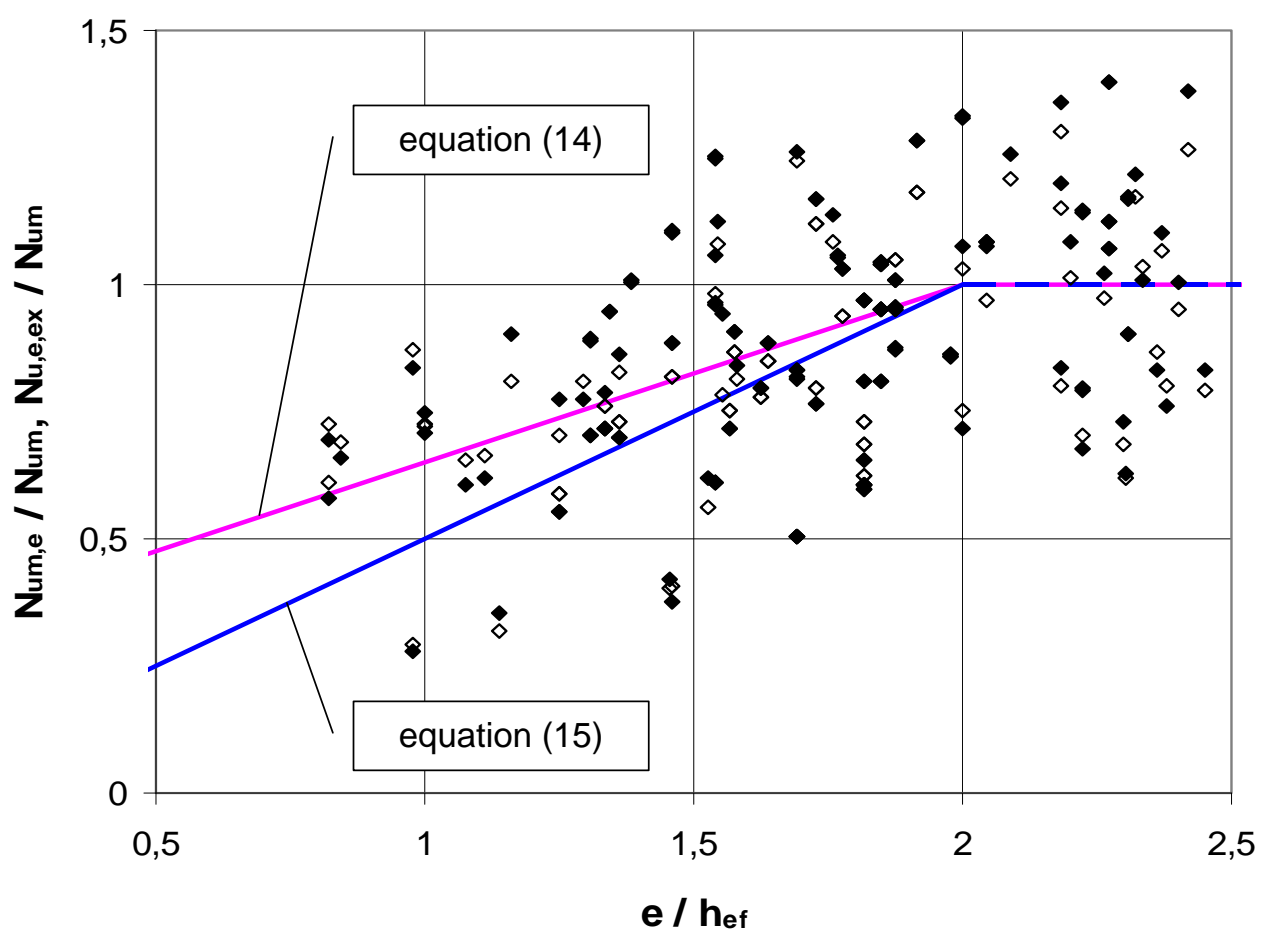

Figure 9. Relationships According to Eqs. 14 and 15

\section{EXPANSION ANCHORS TO CONCRETE UNDER REPEATED LOADING BY TENSILE FORCE}

For experimental verification concrete specimens of the size of $500 \times 400 \times 300 \mathrm{~mm}$ have been used. The concrete cube strength (on the cubes of $150 \mathrm{~mm}$ ) of specimen bodies was ranged from $f_{c c}$ $=20 \mathrm{MPa}$ to $40 \mathrm{MPa}$ and the effective anchor depth was ranged from $h_{e f}=50$ to $60 \mathrm{~mm}$. The anchor bolts of following parameters were used: the steel grade of 8.8 (nominal value of the ultimate tensile strength $f_{u b}=800 \mathrm{MPa}$ ) and diameters of $d=12$ and $16 \mathrm{~mm}$ (the corresponding sleeve diameters $D=18$ and $24 \mathrm{~mm}$ ).

\subsection{Concrete-Cone Failure Mode for Anchor in Large Edge Distance}

For repeated loading only limited number of experiments on the test specimens of various geometrical and mechanical properties was realized. The following partial results were obtained by test data processing and by their evaluation based on the comparison of test "cyclic" tensile strengths with the adequate "static" strengths determined by usual calculating formulas. For typical failure modes the relationships between $N_{c, \max } / N_{u c, s t a t}$ ratio and the number $n$ of loading cycles was derived. The corresponding ultimate "static" strengths for concrete-cone failure were calculated according to Eq. 1 or Eq. 2. For the evaluation of the test results and for their comparison with calculated values of the strengths the regression analysis using the least square method was applied.

For example, based on the " $\psi-$ method" (see above) the ultimate strength of anchor under static tension loading for concrete-cone failure mode can be expressed by Eq. 2. Then, for concrete-cone failure mode the following relationship between $N_{c, \max }$ and $N_{u c, s t a t}$ based on the test results for repeated cyclic loading by tensile force can be derived as follows (Karmazínová $[5,6])$ :

$N_{c, \max }=(0.84-0.04 \cdot \log n) \cdot N_{u c, s t a t}$. 


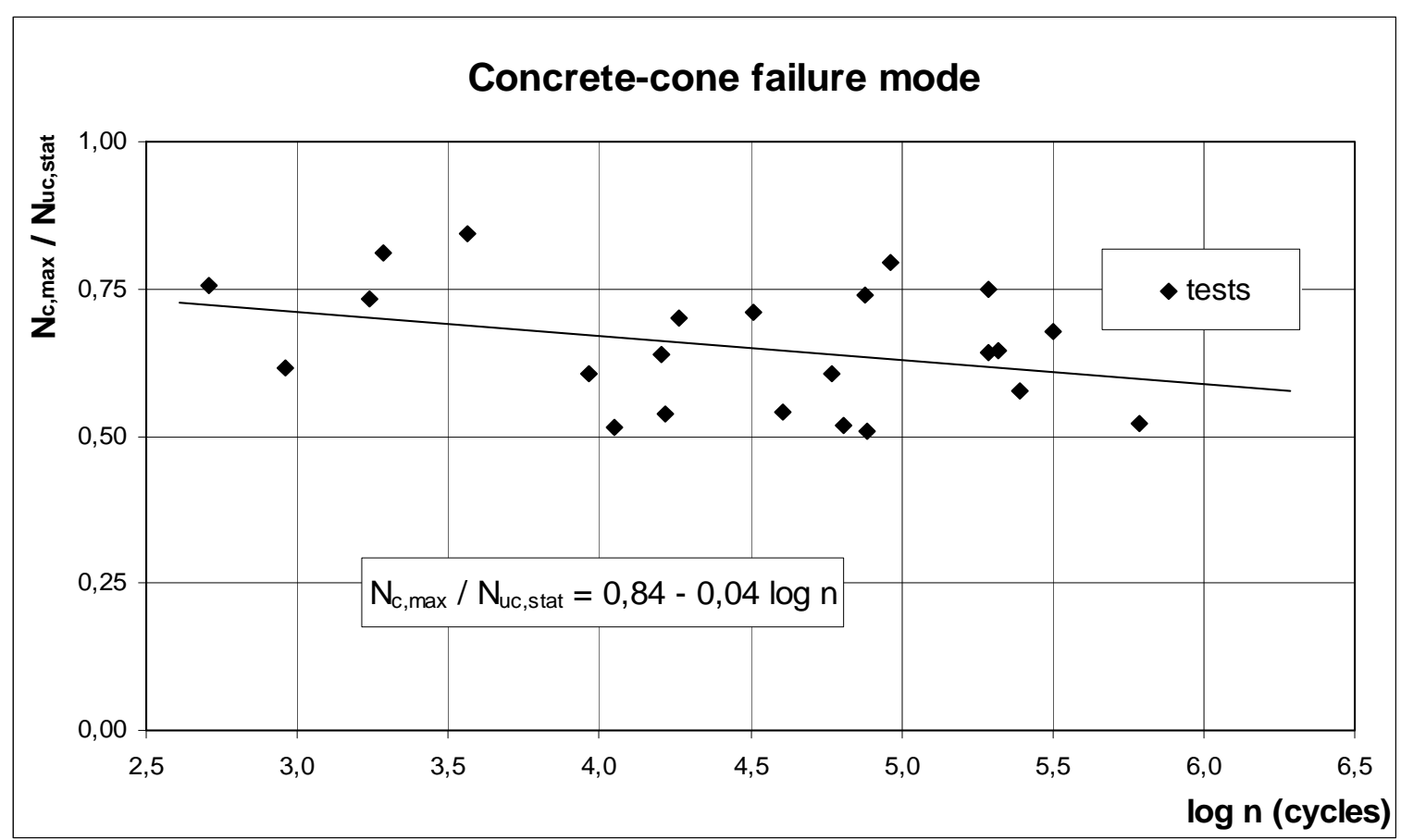

Figure 10. $N_{c, \max } / N_{u c, s t a t}$ Ratio in the Relation to the Number of Cycles $n$ Accord. to (16)

In Eq. 16, which is graphically presented in Figure 10 (in logarithmic scale), $n$ is the number of loading cycles and $N_{u c \text {,stat }}$ is the mean value of load-carrying capacity according to Eq. 2 for concrete-cone failure mode in the case of static tension loading.

\section{EXPANSION ANCHORS TO CONCRETE UNDER STATIC LOADING BY SHEAR FORCE}

For the test specimens under transverse force (shear loading) the expansion torque-controlled anchors with following parameters have been used:

The anchor bolts of following parameters were used: the steel grade of 8.8 (nominal value of the ultimate tensile strength $f_{u b}=800 \mathrm{MPa}$ ) and diameters of $d=10,12$ and $16 \mathrm{~mm}$; the external diameters of anchor sleeve have been $D=14,18$ and $24 \mathrm{~mm}$. The concrete cube strength $f_{c c}$ of the specimen bodies was ranged from 19 to $37 \mathrm{MPa}$, the effective anchor embedment depth $h_{\text {ef }}$ was ranged from 60 to $80 \mathrm{~mm}$ and the anchor edge distance $e$ was ranged from 60 to $195 \mathrm{~mm}$.

\subsection{Lateral Concrete-Cone Failure Mode for Anchor in Small Edge Distance}

For anchors under shear loading realized by transverse force action two basic types of the failure modes - steel failure or concrete failure mode can occur. Mainly here the attention is concentrated to the typical concrete failure mode for anchors placed in small edge distance - lateral concrete-cone failure mode.

For anchors closed to the edge the lateral concrete-cone failure mode in the form of half concrete-cone (see Figure 11) occurred in the case of 43 tests. Similarly as for tension loading also for concrete-cone failure mode (half concrete cone) in the case of shear loading the load-carrying capacity (Karmazínová et al. [4, 6]) can be determined using the principles of two most known methods (Eligehausen [1]) - Concrete Cone Method or Concrete Capacity Method, (methods principles - see Figure 12). 

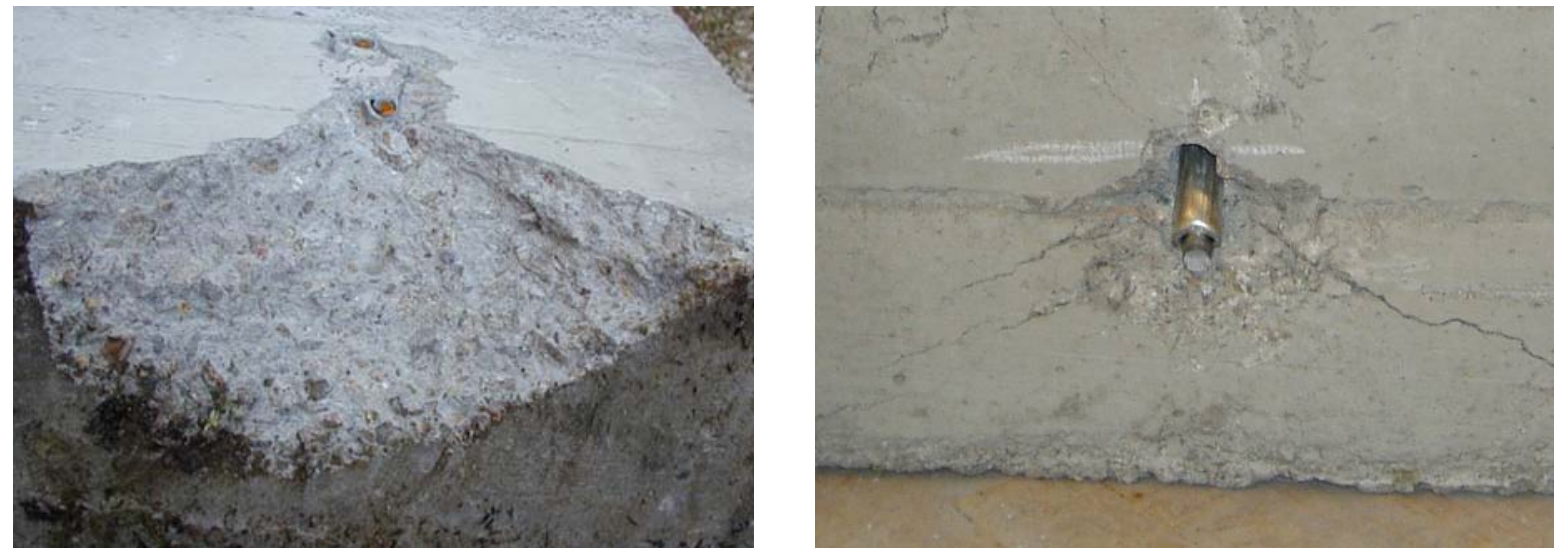

Figure 11. Illustration of Lateral Concrete-Cone Failure (Half Concrete Cone) Mode: Shear Loading, Anchor in Small Edge Distance

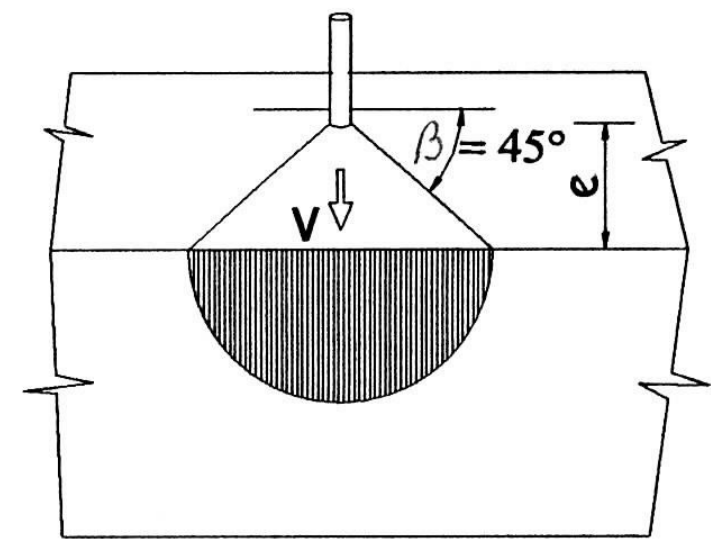

a) $A C I$ - Method

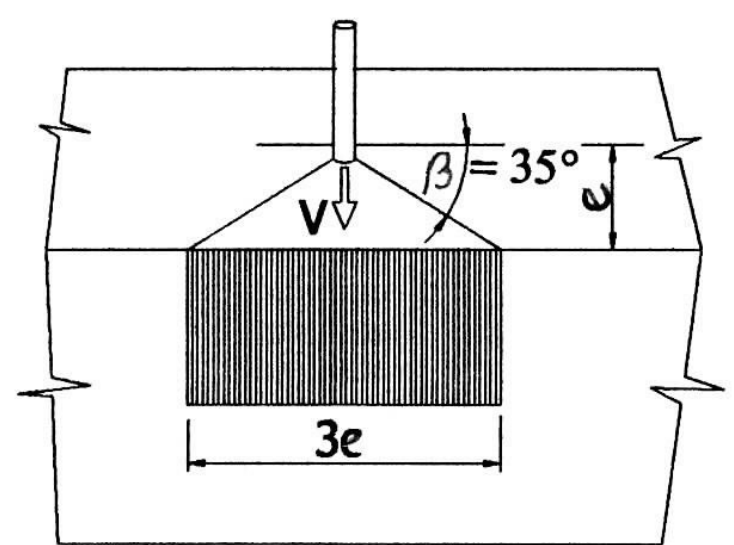

b) $\psi$ - Method

Figure 12. Principles of " $A C I$ " and " $\psi$ " Methods - Lateral Concrete-Cone Failure Mode: Shear Loading, Anchor in Small Edge Distance

For "ACI - method" (see Figure 12a) based on "Concrete Cone Method" the mean value of the load-carrying capacity using the test results can be given by the format of

$$
V_{u m}=0.24 \cdot \pi \cdot e^{2} \cdot f_{c c}^{0.5} \quad[\mathrm{~N}]
$$

where $e$ is the anchor edge distance (see Figure 12) and $f_{c c}$ is the concrete cube strength. For " $\psi-$ method" (see Figure 12b) based on "Concrete Capacity Method" the mean value of load-carrying capacity can be given by the following equation

$$
V_{u m}=7.30 \cdot e^{1.5} \cdot f_{c c}^{0.5} \quad[\mathrm{~N}]
$$

Similarly as for tension loading taking into account also the anchor sleeve diameter $D$ the load-carrying capacity using the test results can be given as following: based on equation (17) the mean value $V_{u m}$ can be written as

$$
V_{u m}=0.199 \cdot \pi \cdot e^{2} \cdot f_{c c}^{0.5} \cdot\left(1+\frac{D}{e}\right) \quad[\mathrm{N}]
$$


based on equation (18) the mean value of load-carrying capacity can be written as

$$
V_{u m}=6.15 \cdot e^{1.5} \cdot f_{c c}^{0.5} \cdot\left(1+\frac{D}{e}\right) \quad[\mathrm{N}] .
$$

For the methods mentioned above (ACI, $\psi$ or methods taking into account also the diameter $D$ ) the statistical parameters of the ratio of the experimental values to the mean values according to Eqs. 17 or 18 and according to Eqs. 19 or 20 are shown in Table 2.

Table 2. Statistical Parameters of the $V_{u, e x} / V_{u m}$ Ratios

\begin{tabular}{|c|c|c|c|}
\hline Statistic Analysis & Mean Value $m$ & Stand. Deviation $s$ & Var. Coefficient $v$ \\
\hline$V_{u m}$ according to (17) & 1.140 & 0.265 & 0.232 \\
\hline$V_{u m}$ according to (18) & 1.001 & 0.201 & 0.201 \\
\hline$V_{u m}$ according to (19) & 1.095 & 0.234 & 0.214 \\
\hline$V_{u m}$ according to (20) & 0.978 & 0.202 & 0.207 \\
\hline
\end{tabular}

In Figures 13 and 14, for the illustration of the expressions of the load-carrying capacity mean values the ratios of experimental to mean values $V_{u, e x} / V_{u m}$ are drawn. In Figure 13 for the Eqs. 17, 18 the ratios $V_{u, e x} / V_{u m}$ depending on the edge distance $e$ are drawn; in Figure 14 for the Eqs. 19, 20 considering also the sleeve diameter $D$ the ratios $V_{u, e x} / V_{u m}$ depending on the anchor sleeve diameter $D$ and also depending on the ratio of $D / e$ respectively, are shown.

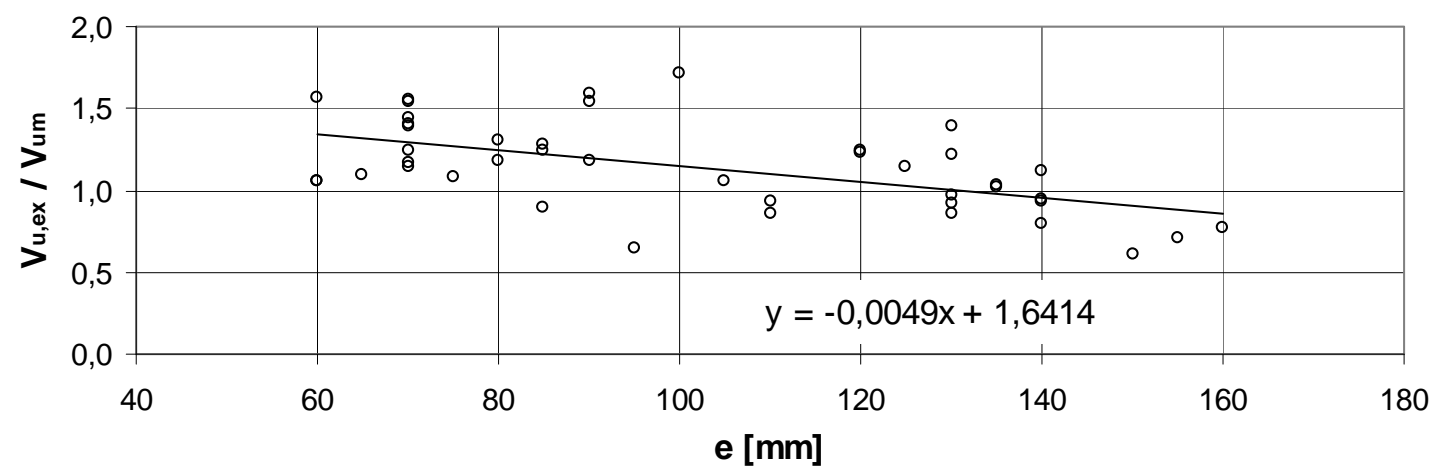

a) Mean Value According to (17)

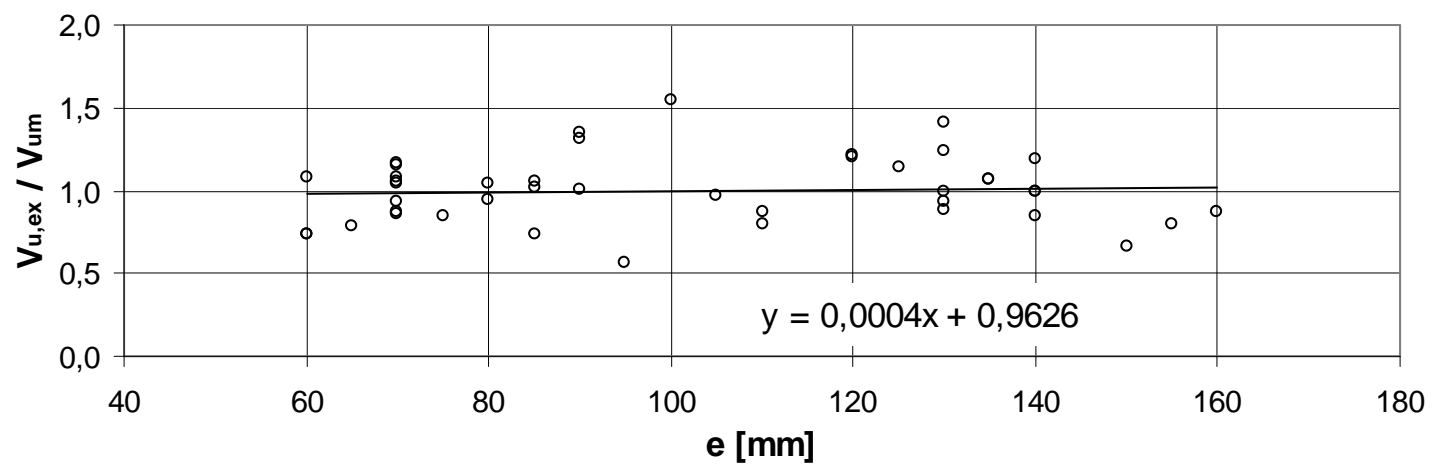

b) Mean Value According to (18)

Figure 13. Ratios of Experimental to Mean Values $V_{u, e x} / V_{u m}$ Depending on $e$ 
The Eqs. 17, 18 and 19, 20 respectively, are useful for the determination of the load-carrying capacity mean values for anchors subjected to shear. Using the procedures of the design assisted by testing (EN 1990 [7]) the load-carrying capacities characteristic and design values $V_{k}, V_{d}$ considering variation coefficients of random variables $\left(e, f_{c c}\right.$ and $D$ respectively) $v_{e}=0.10, v_{f c c}=$ 0.20 (and $v_{D}=0$ respectively) can be determined according to the following formats (Karmazínová et al. $[3,6]$ :

for the mean value according to Eq. 17

$$
\begin{aligned}
& V_{k}=0.110 \cdot \pi \cdot e^{2} \cdot f_{c c}^{0.5} \quad[\mathrm{~N}], \\
& V_{d}=0.066 \cdot \pi \cdot e^{2} \cdot f_{c c}^{0.5} \quad[\mathrm{~N}],
\end{aligned}
$$

for the mean value according to Eq. 18

$$
\begin{aligned}
& V_{k}=4.41 \cdot e^{1.5} \cdot f_{c c}^{0.5} \quad[\mathrm{~N}], \\
& V_{d}=2.87 \cdot e^{1.5} \cdot f_{c c}^{0.5} \quad[\mathrm{~N}],
\end{aligned}
$$

for the mean value according to Eq. 19

$$
\begin{array}{ll}
V_{k}=0.101 \cdot \pi \cdot e^{2} \cdot f_{c c}^{0.5} \cdot\left(1+\frac{D}{e}\right) & {[\mathrm{N}],} \\
V_{d}=0.062 \cdot \pi \cdot e^{2} \cdot f_{c c}^{0.5} \cdot\left(1+\frac{D}{e}\right) & {[\mathrm{N}],}
\end{array}
$$

for the mean value according to Eq. 20

$$
\begin{array}{ll}
V_{k}=3.66 \cdot e^{1.5} \cdot f_{c c}^{0.5} \cdot\left(1+\frac{D}{e}\right) & {[\mathrm{N}],} \\
V_{d}=2.33 \cdot e^{1.5} \cdot f_{c c}^{0.5} \cdot\left(1+\frac{D}{e}\right) & {[\mathrm{N}] .}
\end{array}
$$
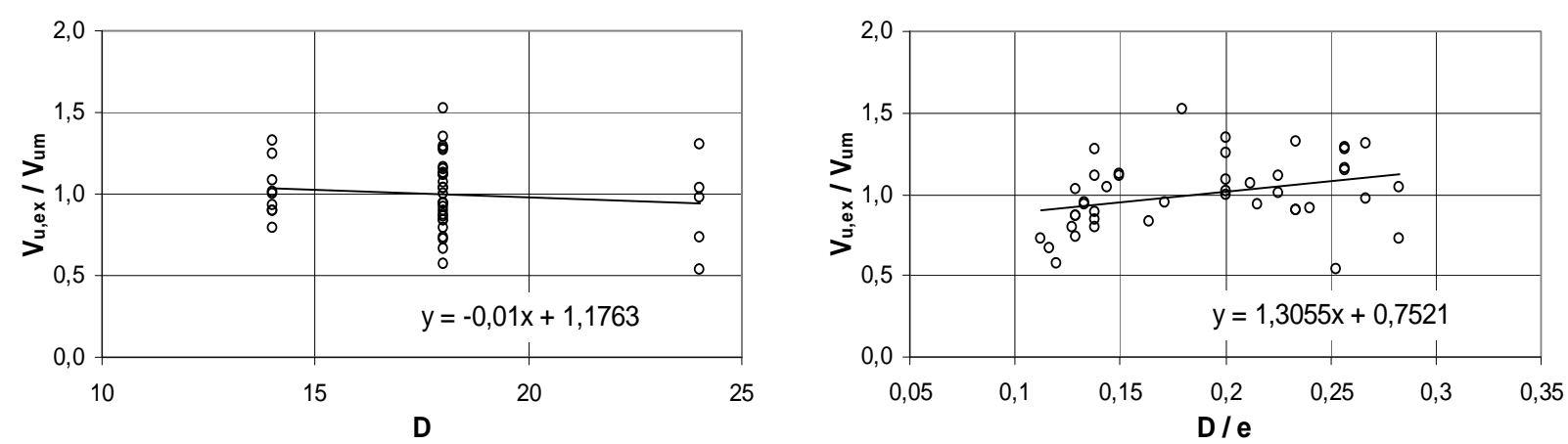

a) Mean Value According to (19) 

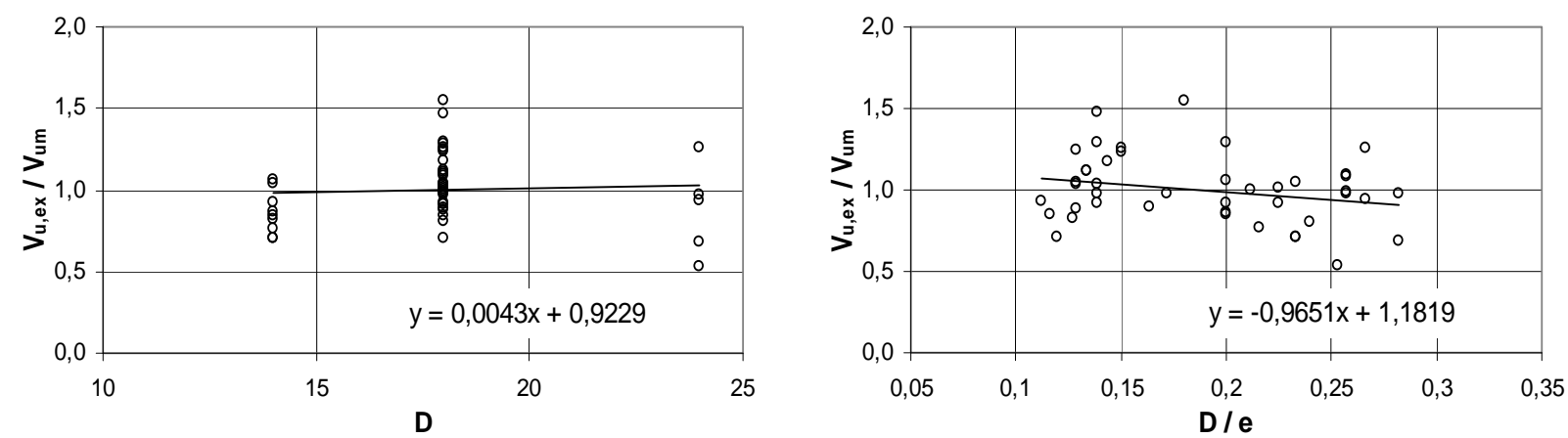

a) Mean Value According to (20)

Figure 14. Ratios of Experimental to Mean Values $V_{u, e x} / V_{u m}$ depending on $D$ and on $D / e$

\section{CONCLUSIONS}

For full concrete-cone failure mode in the case of expansion anchors under tension loading the expressions for the determination of load-carrying capacity based on Eq. 2 or Eq. 4 respectively (with $h_{\text {ef }}$ powered to 1.5) gives lower scatters than the expressions based on Eq. 1 or Eq. 3 respectively (with $h_{e f}$ powered to 2). On the other side, the expressions based on Eqs. 1 or 3 follow the transparent expression of the load-carrying capacity (failure area multiplied by concrete strength) and give higher reliability and safety however they are too conservative comparing the expressions based on Eqs. 2 or 4. Using the formulas taking into account not only the effective embedment depth and concrete strength but also the sleeve diameter $D$, more exact expressions for the load-carrying capacity can be obtained but these ones are not so transparent for the practical use. So the equations going from the format (2) can be taken as the most suitable formulas for the load-carrying capacity expression in the case of full concrete-cone failure mode, for their simplicity, transparency and relevancy.

Adequately, for the expansion anchors subjected to shear, the equations based on (18) or (20) respectively (with $e$ powered to 1.5) are more acceptable formulas for the determination of the load-carrying capacity for lateral concrete-cone failure mode comparing the formulas based on (17) or (19) (with $e$ powered to 2). Then the equations going from the format (17) can be taken as the most suitable formulas for the load-carrying capacity expression in the case of lateral concrete-cone failure mode obtained by shear loading, for the same reasons as in the case of tension loading.

\section{ACKNOWLEDGEMENTS}

This paper has been elaborated with support of the research project of MSMT (Czech Ministry of Education) No. MSM0021630519 and of the GA CR (Czech Grant Foundation) grant projects Nos. 103/06/1107 and 103/07/0628. 


\section{REFERENCES}

[1] Eligehausen, R., Malée, R. and SILVA, J.F., “Anchorage in Concrete Construction”, Ernst \& Sohn, GmbH, Berlin 2006, ISBN 3-433-01143-5.

[2] Karmazínová, M., Melcher, J. and Kala, Z., "To the Design of Steel Expansion Anchors Based on the Experimental Verification of the Actual Behaviour", In Proceedings of the 6th International Conference, Steel and Aluminium Structures ICSAS'07 held in Oxford, Oxford Brookes University, 2007, pp. 401-408, ISBN 978-0-9556254-0-4.

[3] Karmazínová, M. and Melcher, J., "Behaviour of Expansion Anchors to Concrete", In Proceedings of the 2nd International Symposium on Connections between Steel and Concrete held in Stuttgart, IBIDEM - VERLAG, 2007, pp. 279-290, ISBN 978-389821-807-8.

[4] Karmazínová, M., Melcher, J. and Kala, Z., "Load-Carrying Capacity of Post-Installed Steel Anchors to Concrete Subjected to Shear", In Proceedings of the 3rd International Conference on Steel and Composite Structures, ICSCS'07 held in Manchester, University of Manchester, 2007, pp. 449-454, ISBN 0415451418.

[5] Karmazínová, M., "Resistance of the Fastening to Concrete under Repeated Loading", In Proceedings of the 4-th European Conference on Steel and Composite Structures EUROSTEEL 2005, Maastricht 2005, Vol. C, pp. 4.10-33-40, ISBN 3-86130-812-6.

[6] Karmazínová, M., "To the Problems of Design Philosophy and Experimental Verification of Steel Expansion Anchors", Assoc. Prof. Theses, Brno University of Technology, Faculty of Civil Engineering, 2005, pp. 154.

[7] EN 1990 (European Standard), Basis of Structural Design, Brussels: CEN, 2004. 